\title{
On the employment of rotating disks for the study of coloured sensations. The relative intensity of colours
}

\section{A. Rosenstiehl}

To cite this article: A. Rosenstiehl (1882) On the employment of rotating disks for the study of coloured sensations. The relative intensity of colours, Philosophical Magazine Series 5, 13:84, 538-540, DOI: $10.1080 / 14786448208627225$

To link to this article: http://dx.doi.org/10.1080/14786448208627225

曲 Published online: 28 Apr 2009.

Submit your article to this journal $[\pi$

Џll Article views: 2

Q View related articles $\sqsubset$ 
will be varied by employing different metals, different gases, and working under different pressures; I shall have the honour of making known to the Academy the results.-Comptes Rendus de l'Académie des Sciences, May 8, 1882, t. xciv. pp. 1271-1273.

ON THE EMPLOYMENT OF ROTATING DISKS FOR THE STUDY OF COLOURED SENSATIONS. THE RELATIVE INTENSITY OF COLOURS. BY A. ROSENSTIEHL.

In continuing my researches upon the coloured sensations, I have been led to examine a problem which has hitherto appeared inaccessible-that of the relative intensity of colours. What common measure can there be between a red and a yellow, a blue and a violet? It seems at first sight impossible to set up a numerical comparison between values which appear so different in kind ; and yet this comparison is possible, thanks to a well-known special property of the eye.

Between the different colours which have received names an infinity can be intercalated which form the insensible transition from the one to the other without a break. The series is continuous, and closes upon itself like the perimeter of a polygon. Besides (and I cannot sufficiently insist upon the peculiarity), this whole includes an infinity of sensations which, associated in twos, produce a sensation identical for all, that of white. We find nothing analogous in the sensations of the ear; and it is this highly characteristic circumstance that gives a common measure between the different colours.

In my previous Notes, adopting and precisely defining Young's theory, I laid it down as a principle that the sensation of white results from the equal excitation of three primary sensations. Consequently every pair of complementary colours represents in its combination the mixture of the three primary colours at equal intensity. This notion of equal intensity was introduced into a graphic construction, which was discussed; and I verified the principles on which it is based.

It is necessary to distinguish between intensity of coloration and total luminous intensity. By adding the sensation of white in different proportions to a coloured sensation of constant intensity, colours of the same intensity of coloration, but of different total luminous intensity, are obtained. These colours have for their common measure the angle of the sector of the complementary necessary to extinguish all coloured sensation; and, generally, the angle of the sector of the complementary colour is in the inverse ratio of its coloration-intensity. The angle of the white sector ${ }^{*}$ is in the direct ratio of the total luminous intensity.

* It will be remembered that, in all my experiments, the intensity of the sensation of white is measured by the angle of a sector painted white with sulphate of barium, which is set in rapid rotation in front of an absolutely black orifice. 
When the colours have not the same complementary, the graphic construction is indispensable for the determination of the intensity.

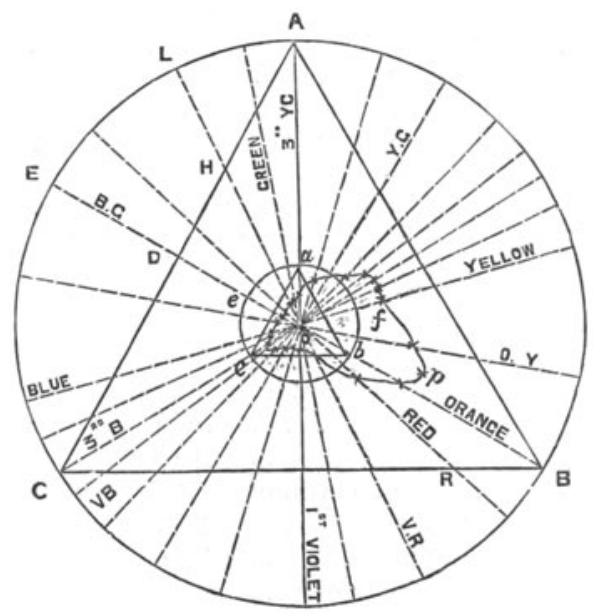

From the point $O, I$ draw three lines $O A=O B=O C$, the length of which is proportional to the intensity of the colours $\mathrm{A}, \mathrm{B}, \mathrm{C}$, which $I$ regard as primary sensations, and which, for that reason, are placed at an augular distance of $120^{\circ}$ from one another. The places of the colours resulting from the mixture, in twos, of the three primary sensations are necessarily upon the sides of the triangle $\triangle B C$. Their distances from the vertices are in the inverse ratio of the coloured sectors necessary to produce them; and their distances from the point $O$ represent their colorationintensities. In this conception the point $O$ is not regarded as the centre of gravity of the triangle; it represents not the place of the white, but the absolute black.

The intensity of the binary colours being given by the construction, it is easy, with the aid of rotating disks, to compare with it the coloured surfaces the intensity of which we wish to know.

Let there be required to find the intensity of coloration of a red surface $\mathrm{S}$. I mix $\mathrm{C}$ and $\mathrm{B}$ so as to obtain red, which I reproduce, in another part, with a sector $\mathrm{S}$, of which the angle $\alpha$ is given by experiment. Let $\mathbf{R}$ (in the figure) be the point occupied by the red; we have

$$
\frac{\mathrm{OR}}{\mathrm{OB}}=\mathrm{I} \frac{\alpha}{360},
$$

from which we get for the intensity of coloration $I$ of the surface $S$

$$
\mathrm{I}=\frac{\mathrm{OR} \times 360}{\alpha \times \mathrm{OB}}
$$

This method is susceptible of verification. Knowing the in- 
tensities of two complementary colours, we know the ratio of their intensities. From this ratio we deduce the angles of the sectors which ought to reproduce the sensation of white-a condition easily verified by direct experiment. The following Table contains the result of this measurement for ten pairs of complementary colours copied upon the chromolithographed circle by M. Digeon, from the chromatic circle of $M$. Chevreul, whose nomenclature I have retained.

\begin{tabular}{|c|c|c|}
\hline \multirow[b]{3}{*}{ 3rd yellow-green and violet } & \multicolumn{2}{|c|}{ Ratio of the coloration-intensities, given } \\
\hline & by the construction. & by direct experiment. \\
\hline & $\ldots \ldots \quad 1 \cdot 17$ & $1 \cdot 25$ \\
\hline 4th green and red $\ldots \ldots \ldots$ & $\ldots \ldots$ & $3 \cdot 73$ \\
\hline Blue-green and orange . . & $6 \cdot 80$ & $6 \cdot 70$ \\
\hline 1st blue-green and orange-ye & llow.. & $6 \cdot 20$ \\
\hline Blue and yellow .......... & $\ldots \ldots$ & $3 \cdot 80$ \\
\hline 2 nd blue and 1 st yellow... & $\ldots \ldots$ & $3 \cdot 18$ \\
\hline 3rd blue and complementary & yellow & $3 \cdot 00$ \\
\hline 4th blue and 2nd yellow.... & $\ldots \ldots$ & $2 \cdot 21$ \\
\hline Violet-blue and 4 th yellow. & $\ldots \ldots$ & $2 \cdot 13$ \\
\hline 2nd violet-blue and yellow-gr & een $\ldots$ & $2 \cdot 00$ \\
\hline
\end{tabular}

The accordance between experiment and construction is one of the most complete, so that the latter can be regarded as summing up exactly the state of our knowledge respecting the mixing of colours. It gives for each the proportion of the primary sensations $\mathrm{CR}: \mathrm{RB}$, the coloration-intensity $\mathrm{OR}$, the complementary $V$, the ratio of the sectors of a pair of complementary colours $\frac{\mathrm{OR}}{\mathrm{OV}}$ necessary to produce the sensation of white, the intensity of that sensation, the total luminous intensity, the triads, \&c.

Having obtained all these concordant numerical results, I could not resist the desire to advance a step further and examine if it was possible to express the intensity of a colour by its ratio to that of white, and thereby to learn what is the distance which still separates the finest colours obtained with colouring-matters from those which the eye is susceptible of perceiving.

In regard to the total Iuminous intensity that ratio has been exactly determined. The finest aniline-blue represents only one fifteenth, and the chromates of lead one seventh, of the intensity of the white obtained, for one and the same illumination, with barium sulphate. For the coloration-intensity the difference would be still greater; and hence it is evident that the chemistry of colouring-matters owes us yet much progress before it can realize what light can give us and what the eye is capable of perceiving.-Comptes Rendus de l'Académie des Sciences, May 22, 1882, t. xciv. pp. 1411-1414. 